\title{
Microstructural and Mechanical Characterization of Chicken Eggshell-Reinforced Al6061 Matrix Composites
}

\author{
Surendra Kumar Dwiwedi', Ashok Kumar Srivastava2 ${ }^{2 *}$, Koh-ichi Sugimoto ${ }^{3}$, Manoj Chopkar ${ }^{4}$ \\ ${ }^{1}$ Department of Mechanical Engineering, SOE, OP Jindal University, Raigarh, India \\ ${ }^{2}$ Department of Metallurgical \& Materials Engineering, SOE, OP Jindal University, Raigarh, India \\ ${ }^{3}$ Department of Mechanical Systems Engineering, Shinshu University, Nagano, Japan \\ ${ }^{4}$ Department of Metallurgical \& Materials Engineering, National Institute of Technology, Raipur, India \\ Email: *ashok.iitkgp@yahoo.co.uk
}

How to cite this paper: Dwiwedi, S.K., Srivastava, A.K., Sugimoto, K. and Chopkar, M. (2018) Microstructural and Mechanical Characterization of Chicken Eggshell-Reinforced Al6061 Matrix Composites. Open Journal of Metal, 8, 1-13. https://doi.org/10.4236/ojmetal.2018.81001

Received: January 31, 2018

Accepted: March 24, 2018

Published: March 27, 2018

Copyright (c) 2018 by authors and Scientific Research Publishing Inc. This work is licensed under the Creative Commons Attribution International License (CC BY 4.0).

http://creativecommons.org/licenses/by/4.0/

\begin{abstract}
Chicken eggshell (ES) is an aviculture byproduct that has been used as the reinforcement in the present study which is recorded worldwide as one of the vilest environmental problems. The present work deals with development of ES-reinforced Al6061 matrix composites by stir-casting process with 0 to 10 wt $\%$ of reinforcement at an interval of $2 \mathrm{wt} \%$. The microstructures of the fabricated composites were examined by optical and scanning electron microscopes with energy dispersive spectrometer (SEM/EDS). Optical micrographs divulge the uniform distribution of reinforcing particles in the matrix while $\mathrm{X}$-ray diffraction (XRD) patterns ensure the dispersion of ES particles reinforcement in Al6061 matrix. The properties measured include density, tensile strength and hardness values. The tensile strength and hardness of composites increase with the addition of ES particles and the maximum values were achieved at $4 \mathrm{wt} \%$. Further increase of ES particles in the matrix leads to decrease in hardness and strength owing to increase in porosity.
\end{abstract}

Keywords

MMCs, Al6061, Eggshell, Stir Casting

\section{Introduction}

Aluminium metal matrix composites (AMCs) are attaining global attention nowadays in the field of aerospace, automobiles, marine, construction etc. due to their superiority over monolithic alloys which includes mechanical and physical properties like low density, high specific strength, stiffness, elastic modulus, 
strength to weight ratio etc. [1] [2] [3] [4]. Al6061 alloy which is a precipitation-hardened aluminium alloy, containing magnesium and silicon as its major alloying elements, is the most widely used matrix material because of its good mechanical properties, ease of fabrication, good castability, weldability and resistance to atmospheric corrosion [5] [6] [7]. It is one of the most common aluminum alloys for general-purpose use. However, it doesn't provide the required properties under all service conditions, which are overcome by reinforcing these alloys with hard particles such as $\mathrm{SiC}, \mathrm{Al}_{2} \mathrm{O}_{3}, \mathrm{~B}_{4} \mathrm{C}$ etc. Reinforcement of hard particles results in achieving enhanced mechanical properties such as: high strength, stiffness and high wear resistance compared to unreinforced alloys but at the expense of some ductility [8] [9] [10] [11].

One essential factor which limits the application of AMCs is their high cost of production due to the use of expensive reinforcement. One of the best way to reduce the cost, is to use low cost reinforcements which include waste materials like fly-ash, red mud, rice husk ash, bagasse ash, maize stalk waste and eggshells waste particles. These waste and naturally available materials offer great opportunity towards the economical development of composites. Increasing demand of these low cost composites has called for global research and most of them are focused on Aluminium and its alloy. Chicken eggshell (ES) is a commonly known waste byproduct when simply disposed causing serious environmental hazards. However, recent investigations highlighted that chicken eggshell can be commercialized to produce new materials because of its renovation potential. Other advantages associated with the use of eggshell waste are its bulk availability at low cost and lightweight property. Although chicken eggshell is a waste product and a lot of health and social issues are associated with it, it is complemented with presence of less dense calcium carbonate which can be commercialized [12]-[18].

It has been reviewed that the potential of ES as a low cost reinforcement due to its availability in bulk in the metal matrix has not been explored much yet. An attempt has been taken to develop ES-reinforced Al6061 composites by stir casting route which is adopted because of its simplicity and it offers better bonding between reinforcement and matrix, wettability and homogeneous distribution of particles in the matrix [19] [20].

\section{Experimental Procedure}

In the present work, Aluminium alloy Al6061 is used as base material and eggshell powder of mesh size $100-120 \mu \mathrm{m}$ is used as the reinforcement. The melting of Al6061 has been performed in the stir casting machine. The chemical compositions of Al6061 alloy is shown in Table 1.

Table 1. Chemical compositions of Al6061 alloy.

\begin{tabular}{cccccccccc}
\hline Element & $\mathrm{Si}$ & $\mathrm{Fe}$ & $\mathrm{Cu}$ & $\mathrm{Mn}$ & $\mathrm{Mg}$ & $\mathrm{Cr}$ & $\mathrm{Zn}$ & $\mathrm{Ti}$ & $\mathrm{Al}$ \\
\hline Percentage & 0.663 & 0.543 & 0.347 & 0.058 & 0.881 & 0.273 & 0.069 & 0.052 & Balance \\
\hline
\end{tabular}


The collected Eggshells were cleaned thoroughly with fresh water and then boiled in water to allow separation of membrane and shell. It was then dried in sunlight for a week. Sun dried ES were pulverized using RETSCH PM400 high energy ball milling machine to convert ES into powder. The ES powders were fed onto sieve set of vibratory sieve shaker machine, arranged in decreasing order of fineness. The set was vibrated for 15 minutes to classify the fineness of powder. Most of the powders get collected in the 100 and 120 mess sieve which were combined together and utilized in the present work.

The composites under investigation were Al6061/ES composite, containing 2 $10 \mathrm{wt} \%$ of reinforcement at an interval of $2 \%$. Standard sample without reinforcement was also prepared. The composites were fabricated by single step stir casting route. The melting of Al6061 alloy was carried out at $750^{\circ} \mathrm{C}$. The eggshell particles were preheated at $500^{\circ} \mathrm{C}$ for an hour. The preheated ES particles were added to vortex melt in a controlled manner to ensure fair uniform distribution of particles in the melt. It was stirred continuously at $500 \mathrm{rpm}$ for 10 minutes and then poured into the preheated mould to produce the cast bars 200 millimeter $(\mathrm{mm})$ long, $20 \mathrm{~mm}$ in diameter. All the composites were prepared by the same process. These cast bars were machined to produce test samples as per ASTM E8M (Length $=60 \mathrm{~mm}$, Gauge diameter $=12 \mathrm{~mm}$ and Grip diameter $=$ $16 \mathrm{~mm}$ ) standards.

The microstructural examination has been carried out by preparing cylindrical samples of $12 \mathrm{~mm}$ diameter and $10 \mathrm{~mm}$ height. Standard metallographic processes have been used for polishing the specimens and all samples are etched with Keller's reagent. Micrographs have been taken on optical microscope (model AxioCam ERc5s, ZEISS). Fractography of fractured surfaces after tensile testing and EDXA elemental analysis of certain phases present in the composites have been carried out using SEM (Model X-max 20, ZEISS) equipped with Oxford instrument Energy Dispersive Spectroscopy (EDS).

Density of samples was calculated using Archimedes principle. The experimental density was calculated using Equation (1) [21] and theoretical density is calculated using Equation (2) known as rule of mixtures [21] [22].

$$
\begin{gathered}
\text { Experimental Density }=\text { Mass } / \text { Volume } \\
\text { Theoretical Density }(\rho)=\rho_{m} \cdot V_{m}+\rho_{E S} \cdot V_{E S}
\end{gathered}
$$

where $m$ is mass of composite specimen in grams $(\mathrm{g}), V$ is the displaced volume of water in cubic centimeter (cc), $\rho_{m}$ is the density of matrix assumed as 2.71 $\mathrm{g} / \mathrm{cc}, V_{m}$ is Weight fraction of matrix, $\rho_{E S}$ is the density of Eggshell powder calculated as $2.2 \mathrm{~g} / \mathrm{cc}, V_{E S}$ is the weight fraction of Eggshell powder. Porosity is calculated by the formula given in Equation (3) [23].

$$
\text { Porosity }=1-(\text { Experimental Density/Theoretical density })
$$

The hardness of each sample was recorded directly from Rockwell tester (model 7005 RHT-D) on H scale with a $3.175 \mathrm{~mm}$ steel ball indenter. Tensile properties were evaluated at room temperature on standard cylindrical speci- 
mens using Instron 5900 series computerized universal testing machine as per ASTM E8M standards with a crosshead speed of $12.5 \mathrm{~mm} / \mathrm{min}$ or $0.5 \mathrm{in} / \mathrm{min}$.

\section{Results and Discussion}

\subsection{Microstructural Study}

Figure 1(a) shows the SEM micrograph of chicken ES. The EDS spectra of the ES particles as shown in Figure 1(b), indicates that it contains $\mathrm{Ca}, \mathrm{O}, \mathrm{C}, \mathrm{Mg}$ and which confirms the formation of calcium carbonate in the form of calcite $\left(\mathrm{CaCO}_{3}\right)$ in the particles. The presence of $\mathrm{CaCO}_{3}$ phase has also been confirmed by XRD.

Figure 2(a) shows the optical micrograph of unreinforced Al6061 matrix alloy. It has been observed that the microstructure consists of $\mathrm{Mg}_{2} \mathrm{Si}$ and $\mathrm{Al}_{12} \mathrm{Mg}_{17}$. The EDS spectra as shown in Figure 2(b) reveals that elements $\mathrm{Al}, \mathrm{Mg}$ and $\mathrm{Si}$ are present in the Al6061 alloy in solid solution and precipitated form of $\mathrm{Mg}_{2} \mathrm{Si}$ and and $\mathrm{Al}_{12} \mathrm{Mg}_{17}$ phases both in the grain and along the grain boundaries (Figure 2(a)). The formation of $\mathrm{Mg}_{2} \mathrm{Si}$ and $\mathrm{Al}_{12} \mathrm{Mg}_{17}$ phases has also been confirmed by XRD.

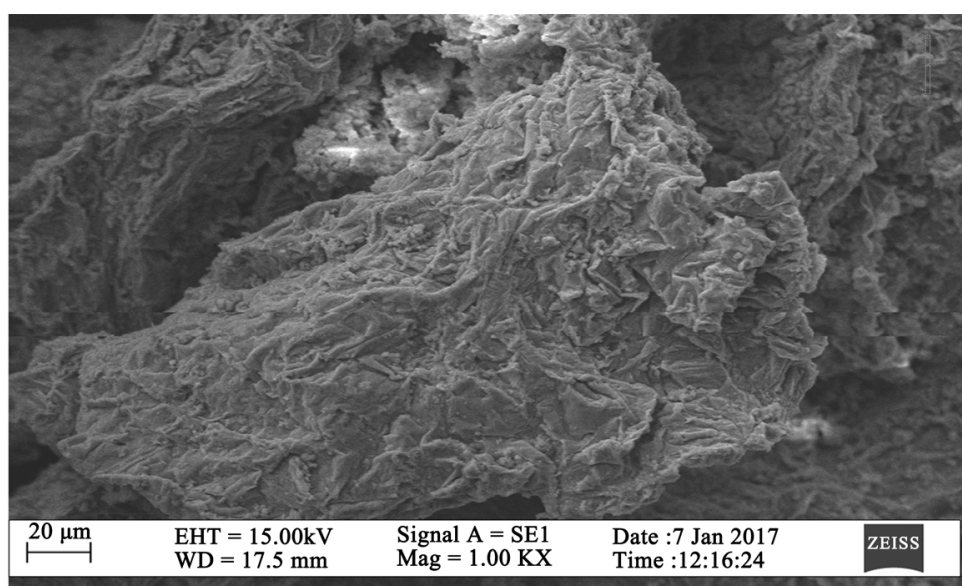

(a)

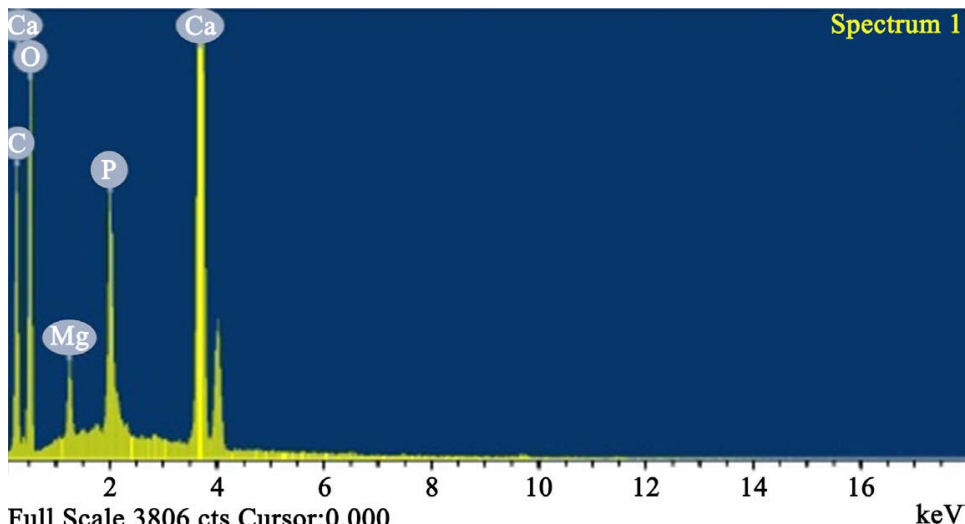

(b)

Figure 1. (a) SEM image of chicken eggshell particle and (b) EDS spectra of chicken eggshell particle. 


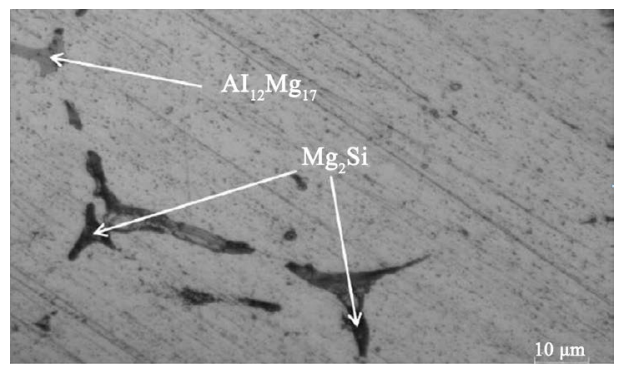

(a)

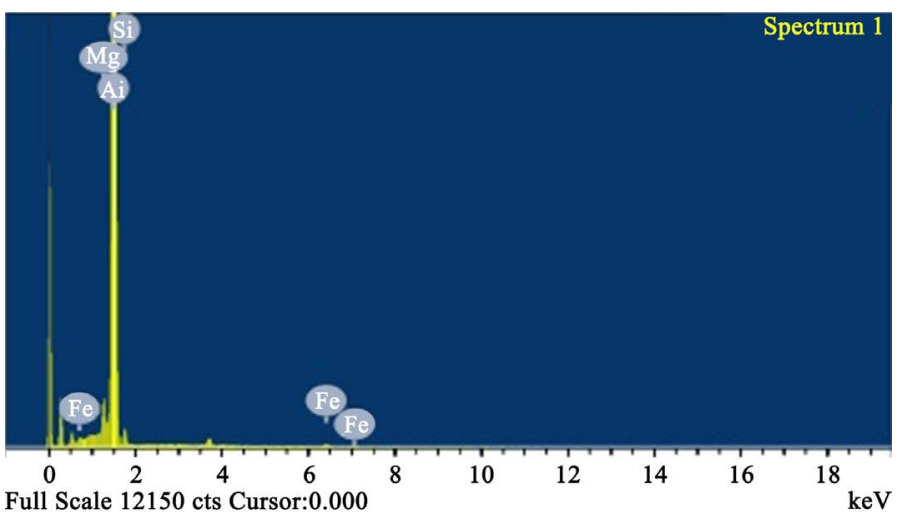

(b)

Figure 2. (a) Optical microsgraph and (b) EDX spectra of as-cast Al6061 matrix alloy.

Figures 3(a)-(e) shows the optical micrographs of ES-reinforced Al6061 alloy matrix composites. The microstructure study shows that ES particles are uniformly distributed in the alloy matrix in the inter-granular as well as intra-granular regions. The dark and white phases are ES particles and matrix respectively. Figure 3(f) shows the EDX of composites which gives clue of some chemical reaction between matrix alloy and ES particles resulted in the release of $\mathrm{Si}, \mathrm{Mg}, \mathrm{Ca}, \mathrm{O}$ and $\mathrm{C}$ in the composite. These constituents may have reacted with $\mathrm{Al}$ present in the molten matrix alloy. Agglomeration and clustering of particles have been observed more in the case the composites with higher wt\% of ES particles resulting in porosity increase.

\subsection{XRD Analysis}

XRD analysis has been conducted to identify the different phases and elements present in the composites. Figure 4(a) and Figure 4(b) shows the XRD patterns of chicken eggshell ES particle and ES-reinforced composites, respectively. It has been observed from Figure 4(a) that the eggshell contains the majority of calcium carbonate $\left(\mathrm{CaCO}_{3}\right)$ phase.

Figure 4(b) shows the XRD patterns of unreinforced and ES-reinforced composites. It shows that the unreinforced Al6061 alloy consists of $\alpha-\mathrm{Al}, \mathrm{Mg}_{2} \mathrm{Si}$ and $\mathrm{Al}_{12} \mathrm{Mg}_{17}$ phases whereas in the composites along with these phases an additional intermetallic compound $\mathrm{CaMgSi}$ phase has been observed. The formation of CaMgSi phase may be due to the interfacial reaction between the 
reinforcement and matrix. It has been observed that peaks slightly shifted towards lower 2-theta in case of the composites compared to the unreinforced

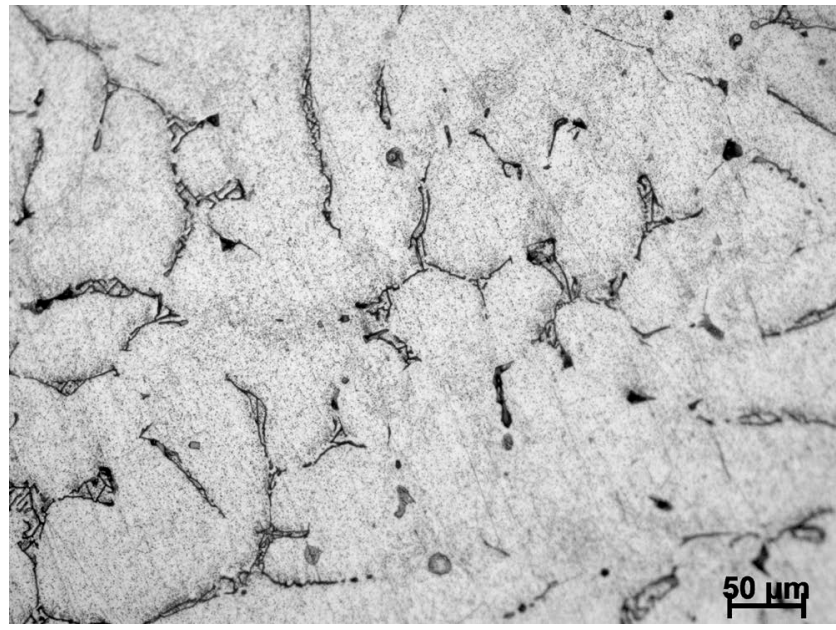

(a)

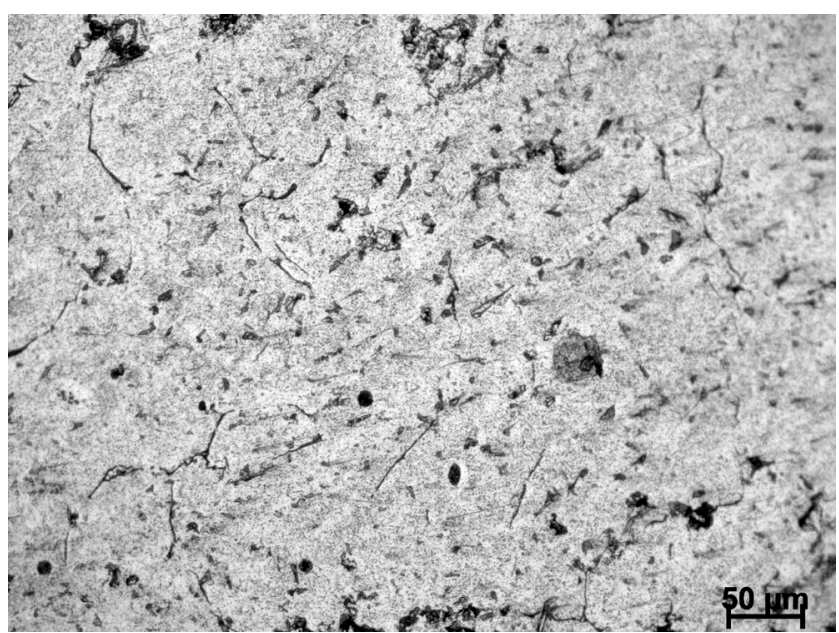

(c)

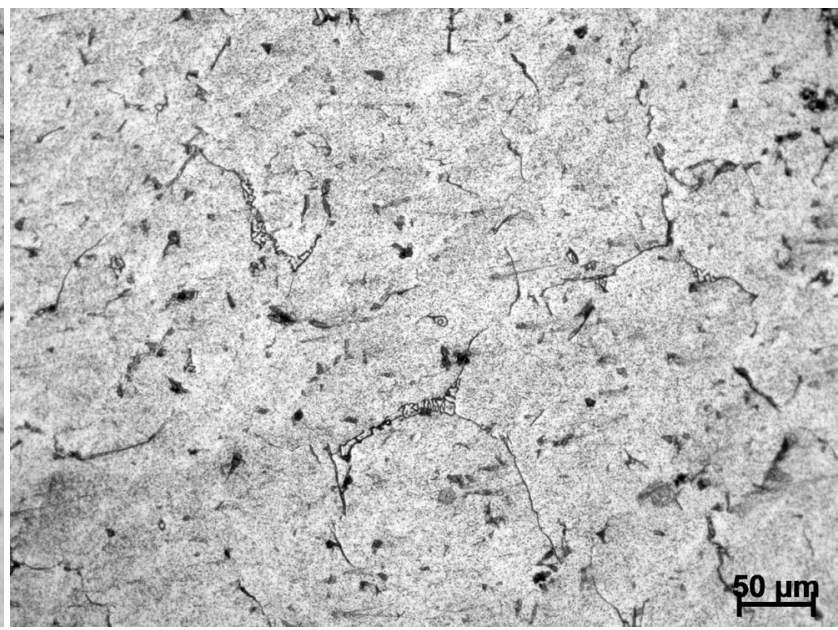

(b)

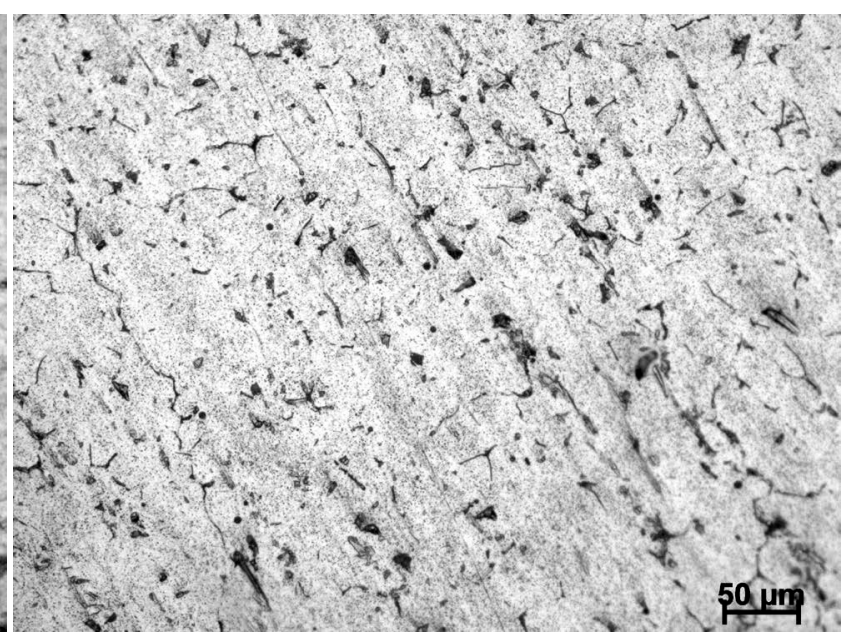

(d)

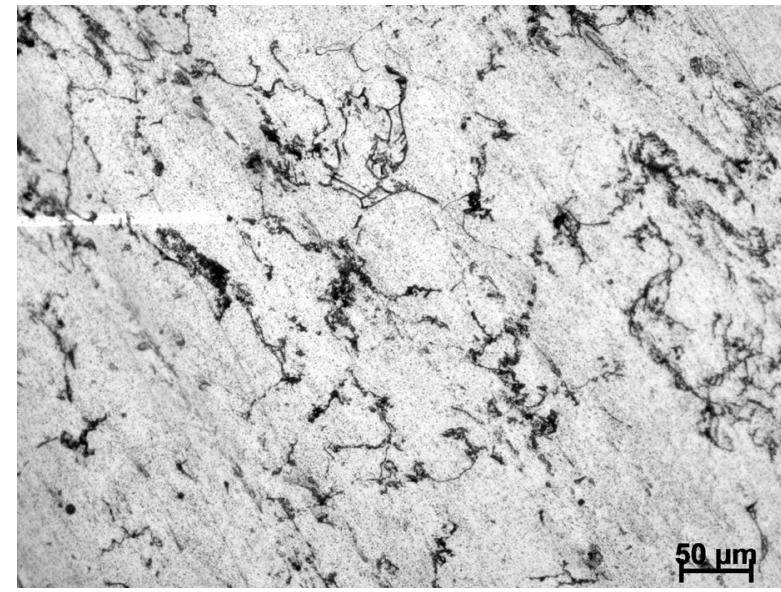

(e)

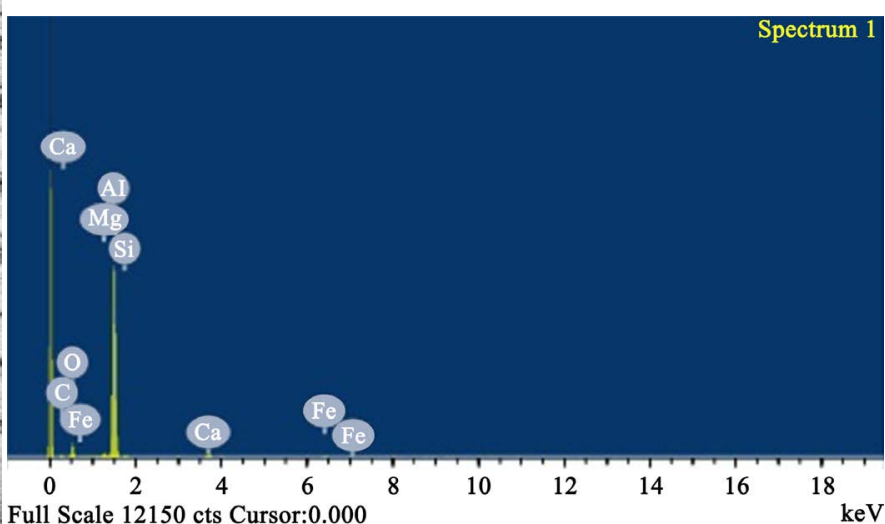

(f)

Figure 3. Optical micrographs ES-reinforced Al6061 alloy matrix composites: (a) 2 wt\%; (b) 4 wt\%; (c) 6 wt \%; (d) 8 wt\%; (e) 10 wt $\%$ of ES and (f) EDS spectra of $4 \mathrm{wt} \%$ composite. 


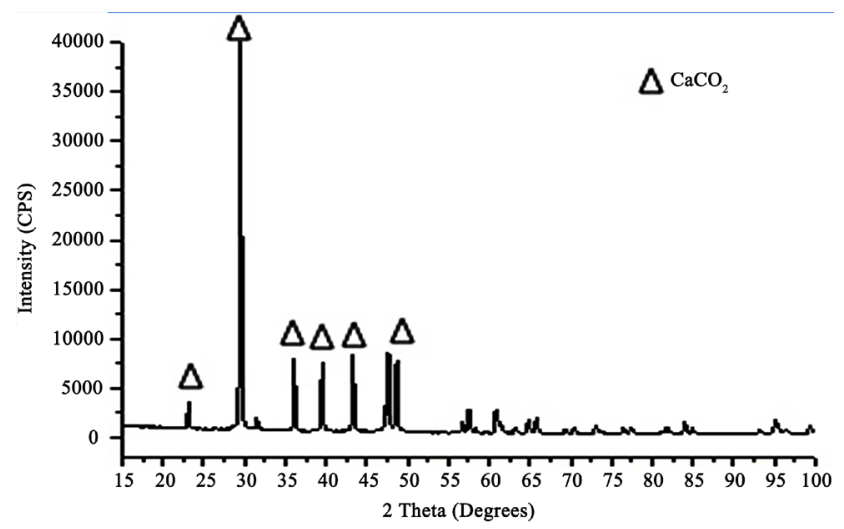

(a)

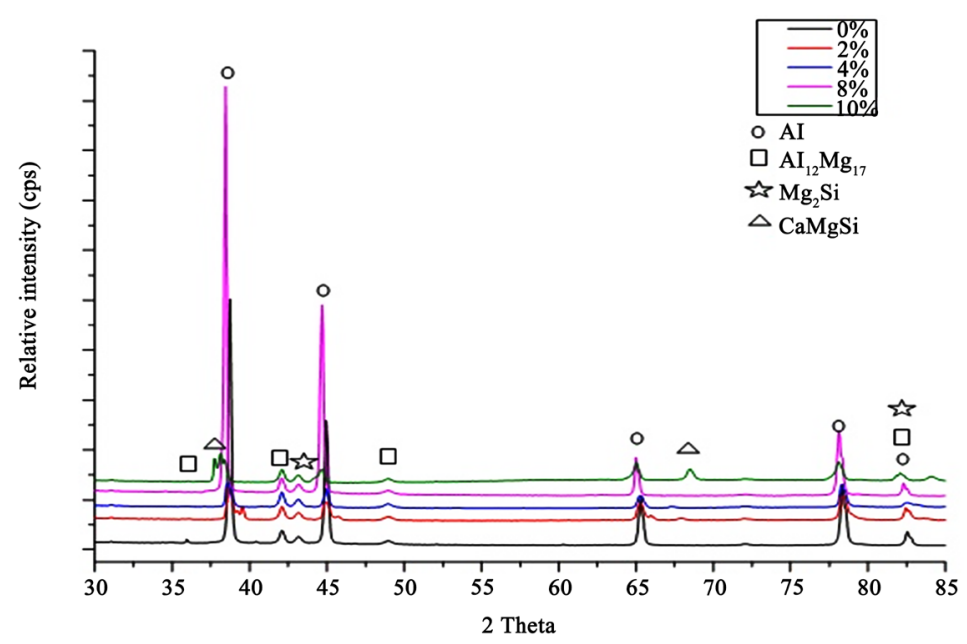

(b)

Figure 4. (a) XRD pattern of eggshell (ES); (b) XRD pattern of composites.

Al6061 alloy suggesting the matrix in the composites has higher value of d-spacing compared to the base alloy which may be due to incorporation of ES particulates. The increased interplanar spacing may be due to the lattice constant of Silicon (Cubic with a $=54.31 \mathrm{~nm}$ ) as $\mathrm{Si}$ is present in small amount in Al6061 and there might be a possibility that Si occupy the interstices and shifts the peak towards left.

\subsection{Density Measurement}

Figure 5(a) shows that both the theoretical and experimental density decreases with increase in reinforcement which may be due to increase in porosity as shown in Figure 5(b). With the increase in reinforcement the viscosity of melt increases and therefore the fluidity of melt are reduced. This invites more gases to get entrapped during casting resulting in porosity. Other reason may be due to the density difference factor between reinforcement and matrix material which causes the particle to float or sink in the melt. The density of ES particle is less than that of the matrix alloy which causes the particles to float on the surface of the melt. For proper mixing, a high stirring speed or time is required which may increase the porosity due to gas entrapment. 


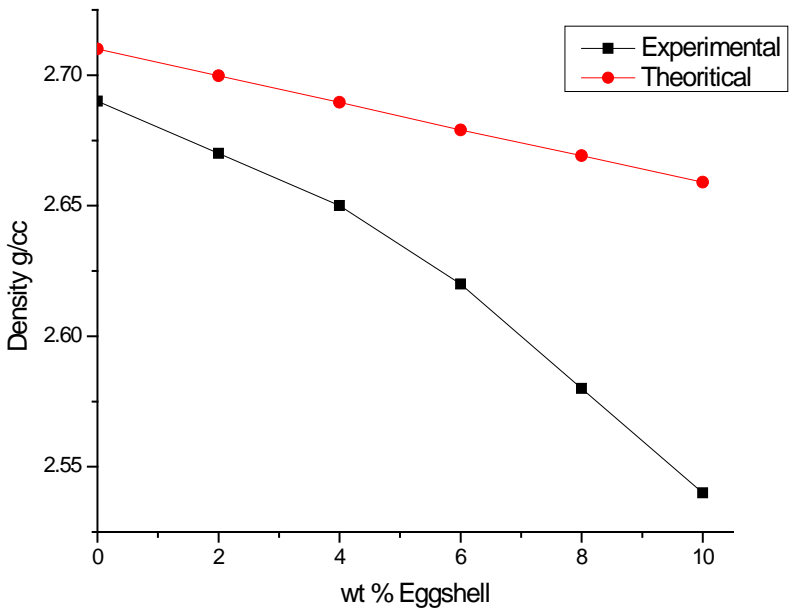

(a)

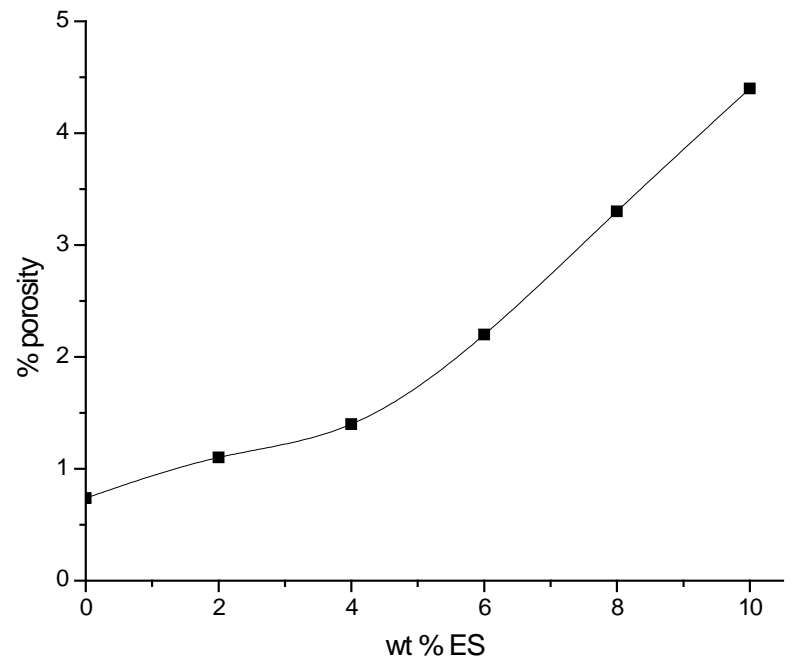

(b)

Figure 5. (a) Variation of density with wt\% of ES; (b) Variation of porosity with wt\% of ES.

\subsection{Hardness and Tensile Strength}

Figure 6(a) and Figure 6(b) shows the variation of hardness and tensile strength of unreinforced and reinforced composites respectively while Figure 6(c) shows the stress-strain curve of different composites. It has been observed that the tensile strength and hardness of composites increase with the addition of ES particles and the maximum values were achieved at $4 \mathrm{wt} \%$. The increases in strength and hardness values are attributed to an increase of the weight percentage of hard and brittle phases of the eggshell particles in the Al6061 alloy matrix. After $4 \mathrm{wt} \% \mathrm{ES}$, further increase of ES particles in the matrix leads to decrease in hardness and strength which may be due to the increased amount of trapped air thereby increasing the amount of pores, as shown in Figure 5(b). The other factors like particle breaking, debonding of particle with matrix due to poor wettability may also be responsible for decrease in hardness and strength with increase in reinforcement. 


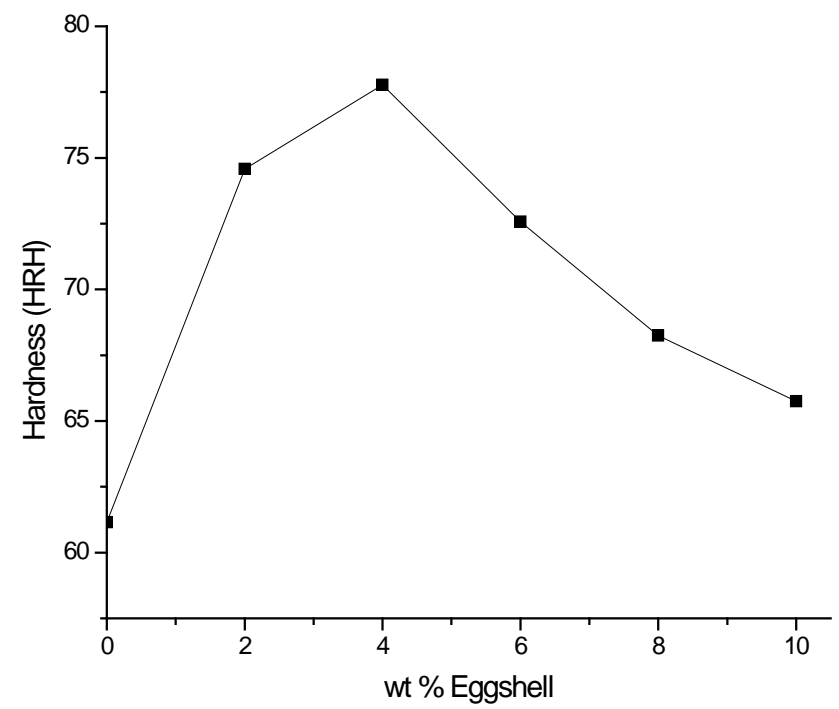

(a)

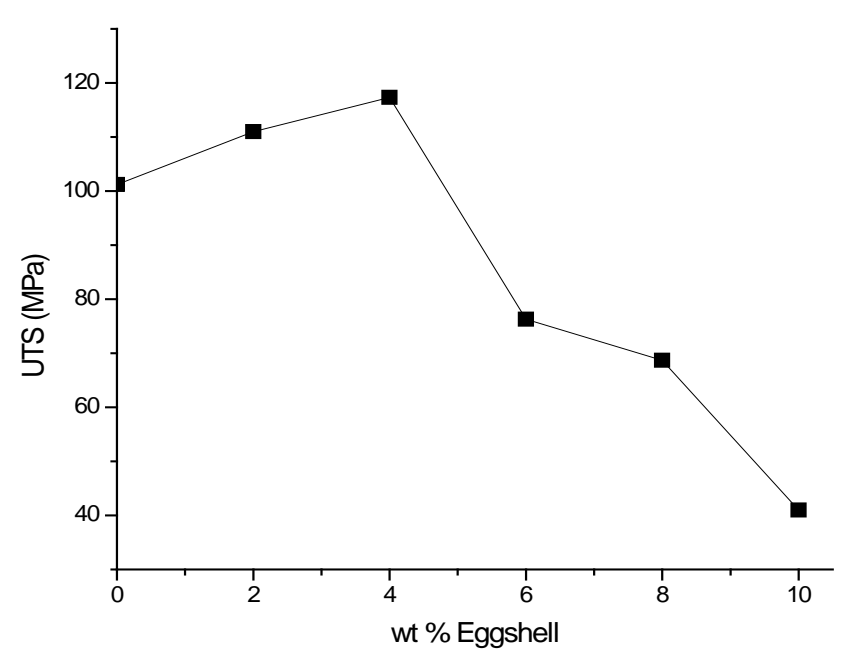

(b)

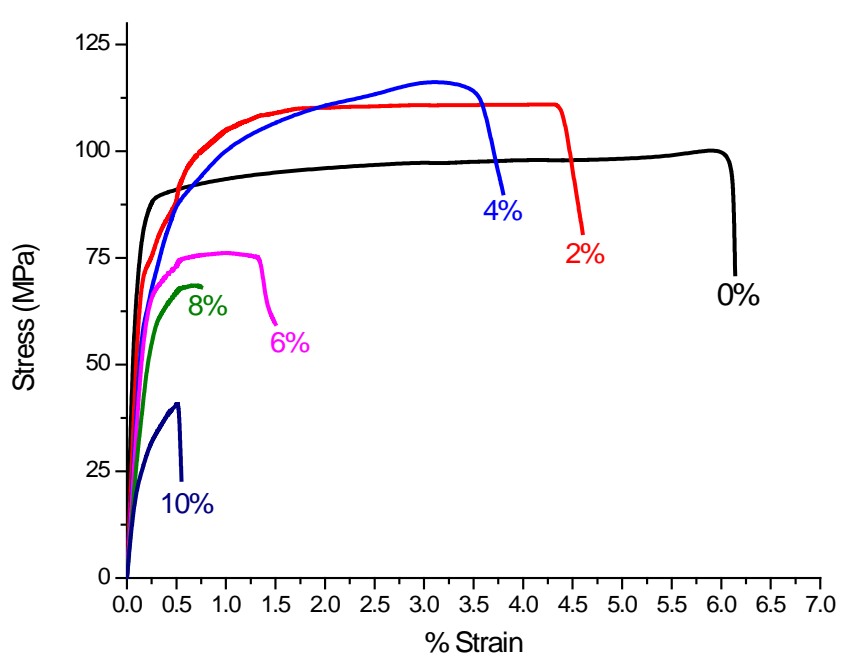

(c)

Figure 6. (a) Hardness variation of composites; (b) Tensile strength variation of composites; (c) Stress-strain curves of unreinforced and reinforced composites.

\subsection{Fracture Studies}

The fracture morphology of tensile test specimens of composites are shown in Figures 7(a)-(f). Figure 7(a) shows the fracture morphology of Al6061 matrix alloy depicting mixed type of brittle and ductile fracture. The presence of bigger and uniformly voids indicates macroscopic ductile fracture and smaller voids and intergranular fracture indicates microscopic brittle fracture. This may be due to presence of brittle $\mathrm{Al}_{12} \mathrm{Mg}_{17}$ intermetallic precipitates along the grain boundaries.

Figures 7(b)-(f) shows the fracture morphology of different composites. The fracture morphology is macroscopically brittle and microscopically ductile as indicated by small stepped microscopically rough fracture surface and smaller voids (Figure 7(b) and Figure 7(c)) due to grain refinement. It revealed no evidence of particle pull out, showing good bonding between matrix and particle. However with 


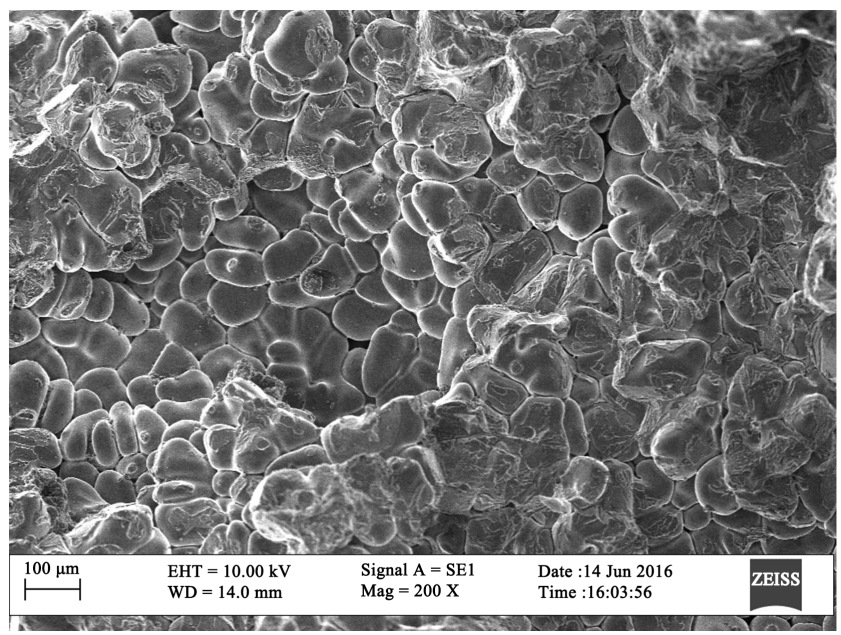

(a)

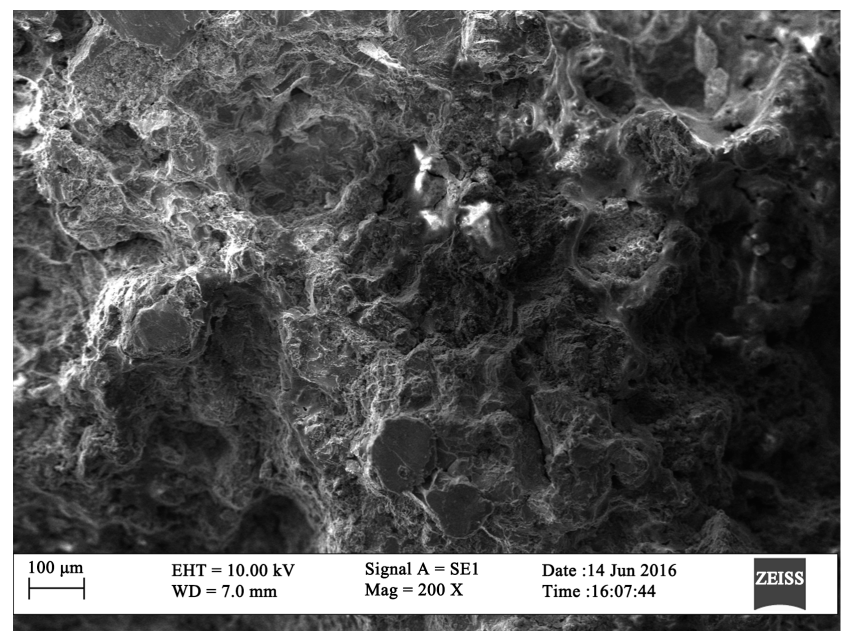

(c)

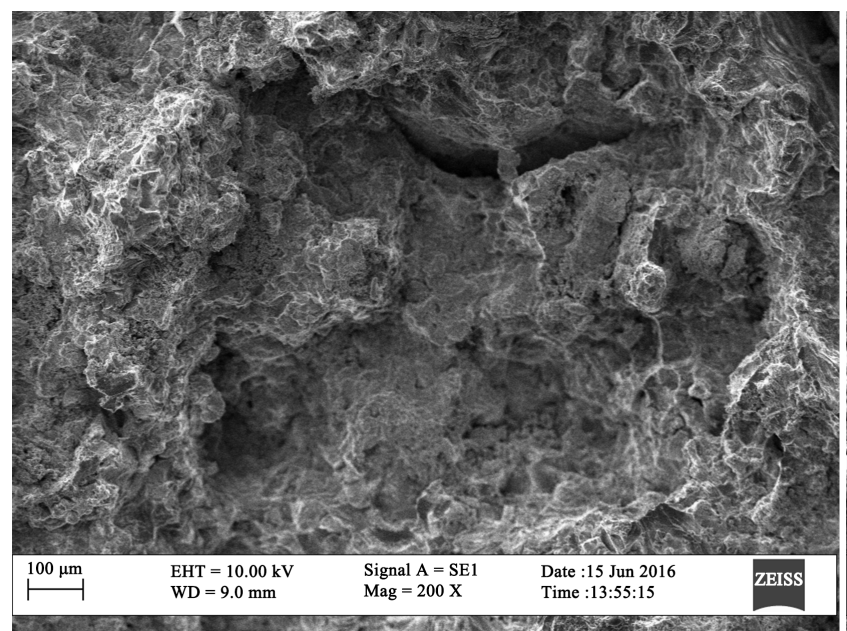

(e)

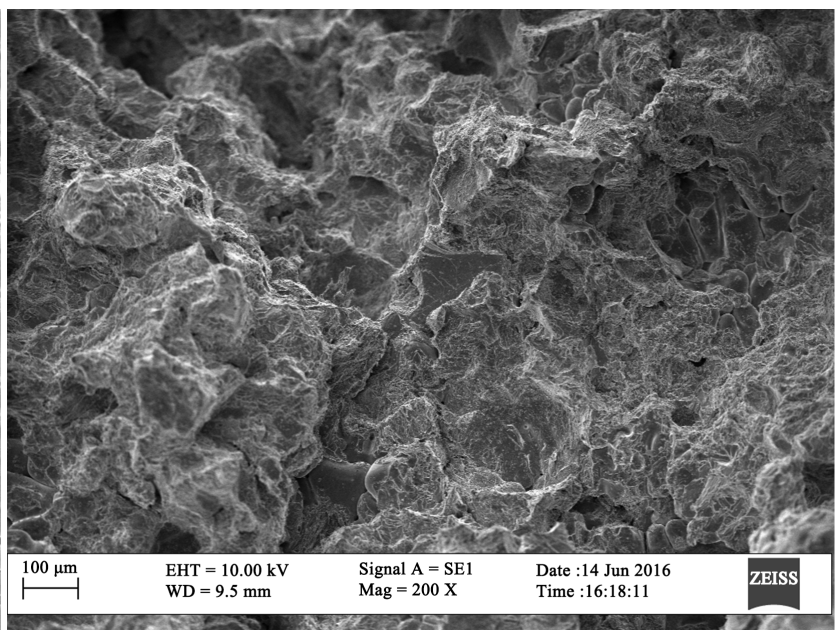

(b)

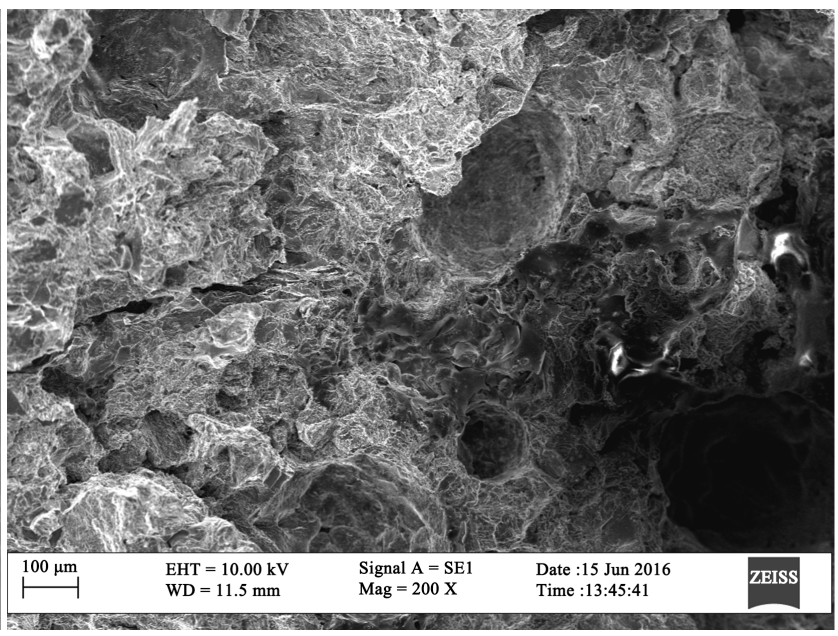

(d)

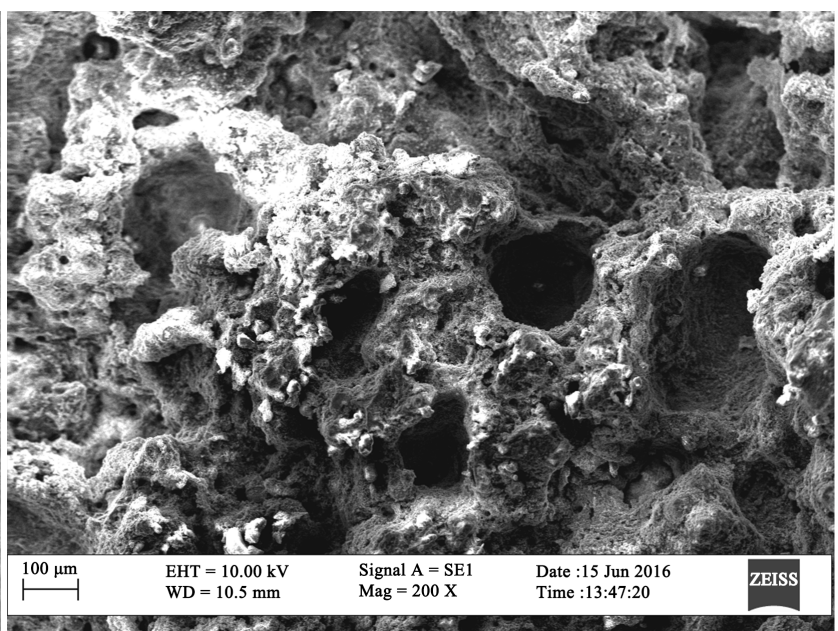

(f)

Figure 7. SEM images of fractured surfaces of (a) $0 \mathrm{wt} \%$; (b) $2 \mathrm{wt} \%$; (c) $4 \mathrm{wt} \%$; (d) $6 \mathrm{wt} \%$; (e) $8 \mathrm{wt} \%$; (f) $10 \mathrm{wt} \%$ at $200 \times$.

increase in reinforcement percentage, the tendency of particle pullout increased (Figures $7(\mathrm{~d})-(\mathrm{f})$ ). The cracks are visible nearby the particle pull out area 
(Figure 7(d) and Figure 7(e)) along with porosity (Figure 7(f)). All such evidence indicates that wettability has reduced drastically when weight percentage of reinforcement is increased. It is observed that ES particle is debonded at the interface (Figure 7(e) and Figure 7(f)) due to weak particle matrix interface resulting in particle pullout. Fracture morphology is transforming from mixed ductile/brittle to completely brittle as reinforcement percentages increased.

\section{Conclusion}

It is found that the chicken eggshell (ES) particles have been successfully incorporated in Al6061 matrix alloy through stir casting technique. The microstructure analysis shows the presence of uniformly distributed ES particles in the matrix alloy. It has been observed that the tensile strength and hardness of composites increases with the addition of ES particles and the maximum values were achieved at $4 \mathrm{wt} \%$. The increase in strength and hardness was resulted due to the increase in the amount of the hard ES phase in the ductile Al6061 alloy matrix which led to increase in dislocation density at the matrix-particle interphase. Further increase of ES particles in the matrix leads to decrease in hardness and strength which may be due to the increased amount of trapped air thereby increasing the amount of pores. It has also been found that with the increase in amount of ES reinforcement the density decreases. With the increase in ES reinforcing particles in matrix, particle pulled out and particle-matrix debonding have been observed which lead to brittle fracture.

\section{References}

[1] Amirkhanlou, S. and Niroumand, B. (2011) Development of Al356/SiCp Cast Composites by Injection of $\mathrm{SiC}_{\mathrm{p}}$ Containing Composite Powders. Journal of Material Design, 32, 1895-1902. https://doi.org/10.1016/j.matdes.2010.12.013

[2] Kala, H., Mer, K.K.S. and Kumar, S. (2014) A Review on Mechanical and Tribological Behaviors of Stir Cast Aluminum Matrix Composites. Procedia Material Science, 6, 1951-1960. https://doi.org/10.1016/j.mspro.2014.07.229

[3] Hassan, S.B. and Aigbodion, V.S. (2015) Effects of Eggshell on the Microstructures and Properties of Al-Cu-Mg/Eggshell Particulate Composites. Journal of King Saudi University-Engineering Science, 27, 49-56. https://doi.org/10.1016/j.jksues.2013.03.001

[4] Rajan, T.P.D., Pillai, R.M. and Pai, B.C. (2007) Fabrication and Characterisation of Al-7Si-0.35Mg/Fly Ash Metal Matrix Composites Processed by Different Stir Casting Routes. Journal of Composite Science and Technology, 67, 3369-3377. https://doi.org/10.1016/j.compscitech.2007.03.028

[5] Dou, Y., Liu, Y. and Xiong, Z. (2014) Friction and Wear Behaviors of $\mathrm{B}_{4} \mathrm{C} / 6061 \mathrm{Al}$ Composite. Journal of Material Design, 60, 669-677. https://doi.org/10.1016/j.matdes.2014.04.016

[6] Maurya, R., Kumar, B. and Ariharan, S. (2016) Effect of Carbonaceaous Reinforcement on the Mechanical and Tribological Properties of Friction Strir Processed Al6061 Alloy. Journal of Material Design, 98, 155-166. https://doi.org/10.1016/j.matdes.2016.03.021

[7] Sanders Jr., R.E. (2001) Technology Innovation in Aluminum Products. JOM, 53, 
21-25. https://doi.org/10.1007/s11837-001-0115-7

[8] Ezatpour, H.R., Sajjadi, S.A. and Sabzevar, M.H. (2014) Investigation of Microstructure and Mechanical Properties of Al6061-Nanocomposite Fabricated by Stir Casting. Journal of Material Design, 55, 921-928.

https://doi.org/10.1016/j.matdes.2013.10.060

[9] Vijay, S.J. and Murugan, N. (2010) Influence of tool Pin Profile on the Metallurgical and Mechanical Properties of Friction Stir Welded $\mathrm{Al}-10 \mathrm{wt} \% \mathrm{TiB}_{2}$ Metal Matrix Composite. Journal of Material Design, 31, 3585-3589.

https://doi.org/10.1016/j.matdes.2010.01.018

[10] Gopalakrishnan, S. and Murugan, N. (2012) Production and Wear Characterization of AA6061 Matrix Titanium Carbide Particulate Reinforced Composite by Enhanced Stir Casting Method. Journal of Composites Part B, 43, 302-308. https://doi.org/10.1016/j.compositesb.2011.08.049

[11] Ashok Kumar, B. and Murugan, N. (2012) Metallurgical and Mechanical Characterization of Stir Cast AA6061-T6-AlNp Composite. Journal of Material Design, 40, 52-58. https://doi.org/10.1016/j.matdes.2012.03.038

[12] Dwivedi, S.P., Sharma, S. and Mishra, R.K. (2016) Characterization of Waste Eggshells and $\mathrm{CaCO}_{3}$ Reinforced AA2014 Green Metal Matrix Composites: A Green Approach in the Synthesis of Composites. International Journal of Precision Engineering and Manufacturing, 17, 1383-1393. https://doi.org/10.1007/s12541-016-0164-Z

[13] Toro, P., Quijada, R., Yazdani Pedram, M. and Arias, J.L. (2007) Eggshell-A New Bio-Filler for Polypropylene Composites. Materials Letters, 61, 4347-4350. https://doi.org/10.1016/j.matlet.2007.01.102

[14] Rath, M.K., Choi, B.H., Ji, M.J. and Lee, K.T. (2014) Eggshell-Membrane Templated Synthesis of Hierarchically-Ordered $\mathrm{NiO}-\mathrm{Ce}_{0.8} \mathrm{Gd}_{0.2} \mathrm{O}_{1.9}$ Composite Powders and Their Electrochemical Performances as SOFC Anodes. Ceramics International, 40, 3295-3304. https://doi.org/10.1016/j.ceramint.2013.09.105

[15] Bootklad, M. and Kaewtatip, K. (2013) Biodegradation of Thermoplastic Starch/Eggshell Powder Composites. Carbohydrate Polymers, 97, 315-320.

https://doi.org/10.1016/j.carbpol.2013.05.030

[16] Sever, L., Nemecek, J., Nedomova, S. and Buchar, J. (2010) Determination of Micromechanical Properties of a Hen's Eggshell by Means of Nanoindentation. Journal of Food Engineering, 101, 146-151. https://doi.org/10.1016/j.jfoodeng.2010.06.013

[17] Hassan, T.A., Rangari, V.K., Rana, R.K. and Jeelani, S. (2013) Sonochemical Effect on Size Reduction of $\mathrm{CaCO}_{3}$ Nanoparticles Derived from Waste Eggshells. Ultrasonics Sonochemistry, 20, 1308-1315. https://doi.org/10.1016/j.ultsonch.2013.01.016

[18] Chaithanyasai, A., Vakchore, P.R. and Umasankar, V. (2014) The Micro Structural and Mechanical Property Study of Effects of Eggshell Particles on the Aluminum 6061. Procedia Engineering, 97, 961-967.

https://doi.org/10.1016/j.proeng.2014.12.372

[19] Ramnath, B.V., Elanchezhian, C. and Jaivignesh, M. (2014) Evaluation of Mechanical Properties of Aluminium Alloy-Alumina-Boron Carbide Metal Matrix Composites. Journal of Material Design, 58, 332-338. https://doi.org/10.1016/j.matdes.2014.01.068

[20] Selvam, J., Robinson Smart, D.S. and Dinaharan, I. (2013) Microstructure and Some Mechanical Properties of Fly Ash Particulate Reinforced AA6061 Aluminum Alloy 
Composites Prepared by Compocasting. Journal of Material Design, 49, 28-34. https://doi.org/10.1016/j.matdes.2013.01.053

[21] Asuke, F., Aigbodion, V.S. and Abdulwahab, M. (2012) Effects of Bone Particle on the Properties and Microstructure of Polypropylene/Bone Ash Particulate Composite. Journal of Research in Physics, 2, 135-141.

https://doi.org/10.1016/j.rinp.2012.09.001

[22] Rohatgi, P.K., Daoud, A. and Schultz, B.F. (2009) Microstructure and Mechanical Behavior of Die Casting AZ91D-Fly Ash Cenosphere Composite. Journal of Composite Part A: Applied Science and Manufacturing, 40, 883-896.

https://doi.org/10.1016/j.compositesa.2009.04.014

[23] Sajjadi, S.A., Ezatpour, H.R. and Parizi, M.T. (2012) Comparison of Microstructure and Mechanical Properties of A356 Aluminum Alloy/ $\mathrm{Al}_{2} \mathrm{O}_{3}$ Composites Fabricated by Stir and Compo-Casting Processes. Journal of Material Design, 34, 106-111. https://doi.org/10.1016/j.matdes.2011.07.037 